\title{
A Promising Material by Using Residue Waste from Bisphenol A Manufacturing to Prepare Fluid-Loss-Control Additive in Oil Well Drilling Fluid
}

\author{
Zhi-Lei Zhang, ${ }^{1}$ Feng-Shan Zhou, ${ }^{1}$ Yi-He Zhang, ${ }^{1}$ Hong-Wei Huang, ${ }^{1}$ Ji-Wu Shang, ${ }^{1}$ Li Yu, \\ Hong-Zhen Wang, ${ }^{2}$ and Wang-Shu Tong ${ }^{1}$ \\ ${ }^{1}$ National Laboratory of Mineral Materials, School of Materials Science and Technology, China University of Geosciences, \\ Beijing 100083, China \\ ${ }^{2}$ Institute of Chemistry, Chinese Academy of Sciences, Beijing 100190, China
}

Correspondence should be addressed to Feng-Shan Zhou; zhoufs@cugb.edu.cn and Yi-He Zhang; zhangyihe@cugb.edu.cn

Received 5 September 2013; Accepted 21 October 2013

Academic Editor: Yizhuang Xu

Copyright (c) 2013 Zhi-Lei Zhang et al. This is an open access article distributed under the Creative Commons Attribution License, which permits unrestricted use, distribution, and reproduction in any medium, provided the original work is properly cited.

\begin{abstract}
The residues mixture from Bisphenol A manufacturing process was analyzed. Fourier transform infrared (FTIR) spectroscopy, gas chromatography-mass spectrometry (GC-MS), and nuclear magnetic resonance (NMR) were used to characterize the residues. The results indicated that the residues were complex mixture of several molecules. 3-(2-Hydroxyphenyl)-1,1,3-trimethyl-2,3-dihydro$1 \mathrm{H}$-inden-5-ol and phenol were the main components of the residues. The technical feasibility of using it as phenol replacement in fluid-loss-control additive production was also investigated. The fluid-loss-control capacity of the novel additive was systematically investigated. It was discovered that the well fluid-loss performance of the prepared additive can be achieved, especially at high temperature.
\end{abstract}

\section{Introduction}

Bisphenol A (BPA) is an organic compound with two phenolic hydroxyl groups [1]. Generally, it is synthesized by condensation of phenol with acetone [2-4]. For reactions involving the substitution of a proton in an aromatic ring, both the rate of reaction and the equilibrium distribution of products are influenced by the density of electrons at the centre of reaction [5]. However, due to the high reactivity of the system, many byproducts can be produced and are present in the reaction mixture. For example, a crude product stream consisted of $41 \% \mathrm{BPA}, 36.2 \%$ ortho,para-isomer, $1.1 \%$ ortho,ortho-isomer, $14.2 \%$ phenol, $3.5 \%$ chromane, $0.05 \%$ flavan, and $12 \%$ of unidentified compounds [6]. The formulas of some by-products are shown in Figure 1. After numerous and diverse purification processes, the impurities (such as the excess phenol, cyclic dimmers derived from BPA, chromanbased compounds, spirobiindane compounds, and the like) were separated from BPA and finally formed the complex residue compound.

Being an important industrial chemical, BPA has been widely used $[7,8]$, and the demand for BPA production has increased [1]. With the growing production of BPA [9], there will be more and more residues from the BPA industry. It is predicted that there will be over $50 \times 10^{3}$ ton residues produced annually in China. According to European Waste Catalogue (EWC), the residues are absolute hazardous $\left(\begin{array}{lll}07 & 01 & 08^{*}\end{array}\right)$. So, appropriate disposal and recycling of the residues are necessary for environmental protection and public health. The residues are generally burned as a means of disposal. Because the incineration technology is not qualified; treatment and recycling of the residues in China have been a thorny problem. The previous researches mainly concentrated on the treatment of the by-products and recovery of the useful phenol [10-12]. Hence, it is imperative to develop methods to utilize the industry waste. So far, there have 
<smiles>CC(C)(c1ccc(O)cc1)c1ccccc1O</smiles>

o,p-isomer<smiles>CC(C)(CC(C)(c1ccc(O)cc1)c1ccc(O)cc1)c1ccc(O)cc1</smiles>

Triphenol<smiles>CC1(C)CC(C)(c2ccc(O)cc2)Oc2ccccc21</smiles>

Flavan<smiles>CC(C)(c1ccccc1O)c1ccccc1O</smiles>

o,o-isomer<smiles>CC1(C)CC(C)(c2ccc(O)cc2)c2ccccc2O1</smiles>

Chroman<smiles>CC1(C)CC2(CC(C)(C)c3ccc(O)cc32)c2ccc(O)cc21</smiles>

Spirobiindane

FIGURE 1: Formulas of the impurities.

only been relatively limited researches in this respect. The residues have been used in furan no-bake foundry binders and phenolic-based foundry shell resin formulations [13].

The petroleum drilling fluids, more commonly known as drilling muds, are complex chemical systems necessary for oil development. Among other functions, a drilling mud needs to create a thin low-permeability cake that protects permeable production formations. Fluid-loss-control additives form filter cakes surrounding the well bore to retard the loss of drilling fluid into permeable formations [14-17]. It has been common practice in the oil well drilling industry to employ starches, starch derivatives, cellulose derivatives, and water-soluble gums to reduce the filtrate volume of water base muds. Although these materials reduce the fluid loss of drilling muds, they are not thermally stable. Generally, watersoluble sulfonated phenolic condensate is obtained from the reaction of phenol, formaldehyde, and anhydrous sodium sulfite [18]. As a drilling mud additive, it has good fluidloss-control performance and resistance to high temperature [19]. However, when the treated muds are subjected to extreme thermal environments, such products should be further modified to enhance the properties. And with raw material prices, the commercial pressure of competition is also growing. Utilization of waste materials for modification or substitution of primary resources has been a widespread concern [20-22]. Phenol has an ortho-para directing activation group, hydroxyl. It could be condensed and sulfonated to produce a fluid-loss-control additive under the presence of formaldehyde and sodium sulfite. Although there are many complicate components coexisting in the residues, most of them have the activation group hydroxyl and could react like phenol. The condensation polymerization by using this kind of residues is more likely a copolycondensation. The resultant products will have the same essential functional group as the products from condensation and sulfonation by using phenol. So, it is feasible by using the residues to displace phenol as a raw material to produce fluid-loss-control additive.

The purpose of this study was to confirm the components of the residue mixture and evaluate the technical feasibility of using it as phenol replacement in fluid-loss-control additive production.

\section{Experimental Details}

2.1. Materials. The residues mixtures were obtained from Nanjing Zunyu Chemical Co., Ltd., China. It was obvious that the waste material was shiny black solid (Figure 2(a)). It was 


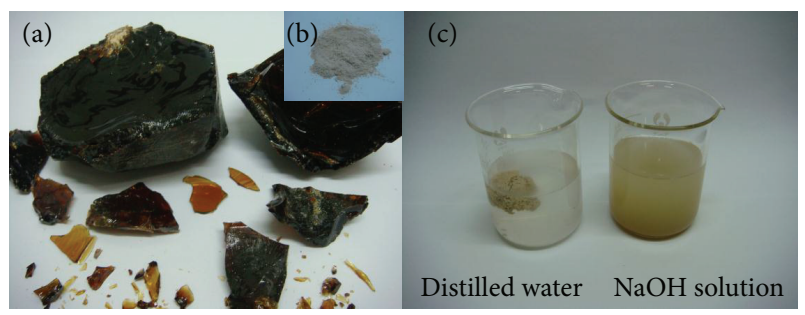

FIGURE 2: Comparison between the residues before (a) and after (b) grinding and the dispersion in distilled water and $\mathrm{NaOH}$ solution (c).

highly brittle, and the powder (Figure 2(b)) could be obtained after grinding. And then, the powder was stirring under the refluxing temperature in distilled water and sodium hydroxide $(\mathrm{NaOH})$ solution for an hour, respectively. In Figure 2(c), the dispersion of the powder was markedly different. In distilled water, the powder was gathering into a mass slowly, but it dispersed well in the $\mathrm{NaOH}$ solution. The raw bentonite was obtained from Dagang Oilfield (Group) Co., Ltd., Tianjin, China. The sulfonated methyl phenolic resin obtained from the Third Exploration Company of Tarim Petroleum Exploration and Development Headquarters was marked as $\mathrm{M}_{1}$ and obtained from Derun Chemical Co., Ltd., Binzhou, China, and was marked as $\mathrm{M}_{2}$. Sulfonated lignite obtained from Hairong Industry \& Trade Co., Ltd., Korla, China, and Beijing Institute of Exploration Engineering was marked as $\mathrm{M}_{3}$ and $\mathrm{M}_{4}$, respectively. All the chemicals such as phenol, formaldehyde, sodium sulfite, sodium bisulfite, sodium hydroxide, sodium chloride, acetone, and cyclohexane were analytical grade and obtained from Beijing Chemical Plant, China. A homemade column chromatograph with a length and width of $40 \mathrm{~cm}$ and $3 \mathrm{~mm}$, respectively, packed with silica gel (ZCX.H, 200-300 mesh size, Branch of Qingdao Haiyang Chemical Plant, China) was used in the study. Standard HSGF254 HPTLC plates $(100 \times 25 \mathrm{~mm})$ were purchased from Yantai Chemical Industry Research Institute, China.

2.2. Methods. FTIR was conducted on the residues on a Perkin-Elmer SP100 FTIR spectrometer by the $\mathrm{KBr}$ disc technique. It was operated in the ATR (attenuated total reflectance) mode, and 32 scans were collected at a resolution of $4 \mathrm{~cm}^{-1}$.

An Agilent Technologies 7890A gas chromatograph equipped with the Agilent 5975C mass spectrometer (Agilent 7890A/5975C GC-MS System) was used to identify the organic compositions. The system was operated at $40^{\circ} \mathrm{C}$ for $1 \mathrm{~min}$ and then up to $300^{\circ} \mathrm{C}$ at a ramping rate of $10^{\circ} \mathrm{C} / \mathrm{min}$ and held for $5 \mathrm{~min}$. One $\mu \mathrm{L}$ of the samples was injected in split mode with a split ratio of $10: 1$. An Agilent J\&W column, with $30 \mathrm{~m}$ in length, $0.25 \mathrm{~mm}$ internal diameter, and $0.25 \mu \mathrm{m}$ film thicknesses was adopted in the separation system. Highpurity helium was the carrier gas and introduced at a constant rate of $1.4 \mathrm{~mL} / \mathrm{min}$.

The eluent used in the column chromatography experiment was an acetone/cyclohexane (1/5, v/v) mixture which was determined by previous thin-layer chromatography experiments. The materials obtained by column chromatography were dried at $50^{\circ} \mathrm{C}$ for $24 \mathrm{~h}$ in a vacuum oven to a constant weight. Nuclear magnetic resonance spectra $\left({ }^{1} \mathrm{H}-\mathrm{NMR}\right.$, $400 \mathrm{MHz}$ ) were acquired on a Bruker-400 spectrometer with the $1 \mathrm{~mm}$ TXI micro liter probe using deuterated chloroform as the solvent.

The fresh-water base mud containing $50 \mathrm{~g} / \mathrm{L}$ of sodium bentonite was prepared by mixing the raw bentonite and fresh water at a certain ratio, stirring for $15 \mathrm{~min}$ at a high speed of 10,000 rpm and aging for $24 \mathrm{~h}$ at room temperature. The testing mud was obtained with an addition of fluid-losscontrol agents and/or sodium chloride into the base mud.

The fluid-loss-control properties of the muds, including API filtrate volume (i.e., $\mathrm{FL}_{\mathrm{API}}$ ) and high-temperature/highpressure filtrate volume (i.e., $\mathrm{FL}_{\mathrm{HTHP}}$ ), were determined according to American Petroleum Institute (API) specifications and Chinese SY/T5621-93 specifications, respectively. In this test process, a ZNS-2A medium-pressure and GGS422 high-pressure filtration apparatus (made by Qingdao Haitongda Special Instruments Co., Ltd., China) were used. Figure 3 shows the schematic of the filtration apparatus. The rheological parameters, such as apparent viscosity (AV), plastic viscosity (PV), and yield point (YP), were determined by a ZNN-D6 rotating viscometer.

2.3. Preparation of Fluid-Loss-Control Additive RPF. A 3-neck flask with a stirrer, thermometer, and reflux condenser was charged with the residues, formaldehyde water solution $(37 \%$ $\mathrm{w} / \mathrm{w})$, sodium hydroxide, and water. The mixture was heated slowly to a certain temperature. After stirring for about an hour, a second portion of formaldehyde water solution, sodium hydroxide and water was added into the mixture with sodium sulfite and sodium bisulfite. After synthesis, the production was pan-dried at $70^{\circ} \mathrm{C}$ and then crushed into powders over 80 mesh sieve for use in mud tests. The nomenclature of this fluid-loss-control additive is designated as RPF here. And the PF was prepared using phenol to replace the residues. Furthermore, there are very little by-products produced from this process which is environmentally green.

2.4. Orthogonal Array Experimental Design. In the present study, an L25 (56) orthogonal array (OA) was used to investigate the effect of formulas and parameters. The orthogonal array was listed in Table 1, and the data analysis was carried out through the range analysis. After the orthogonal experiments and subsequent data analysis, the magnitudes were reflected.

\section{Results and Discussion}

3.1. Spectroscopy Analysis. The infrared spectrum of the residues with the characteristic hydroxyl group stretching band at $3424 \mathrm{~cm}^{-1}$ can be observed in Figure 4. The hydroxyl group band in the residues and RPF does not as strong as that in the PF. This could be attributed to the complex components of the residues and RPF. The absorption peaks at $2962 \mathrm{~cm}^{-1}$ and $1468 \mathrm{~cm}^{-1}$ can be assigned to the vibrational modes of methyl and/or methylene. The peaks at $1605 \mathrm{~cm}^{-1}$ 


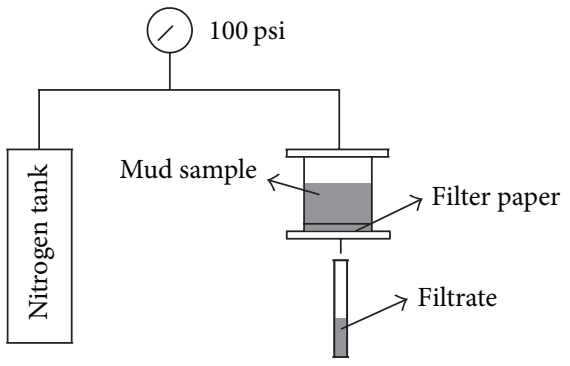

(a)

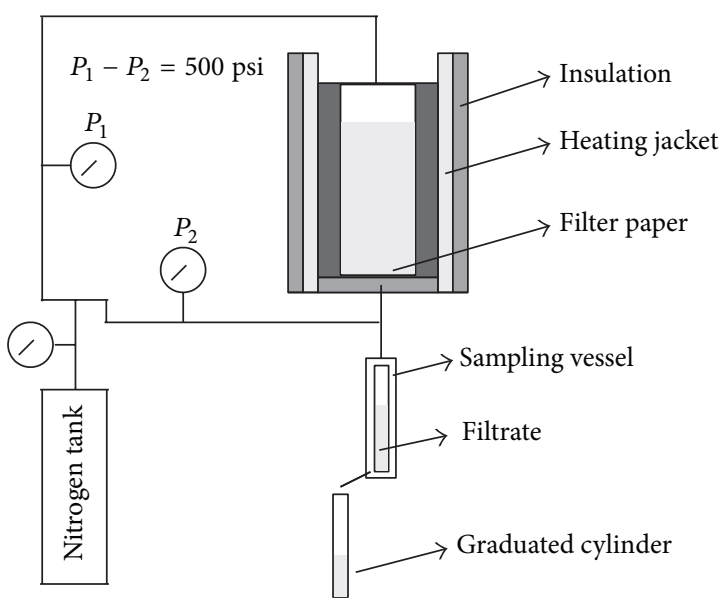

(b)

FIgURE 3: Schematic of the API (a) and HTHP (b) filtration test apparatus.

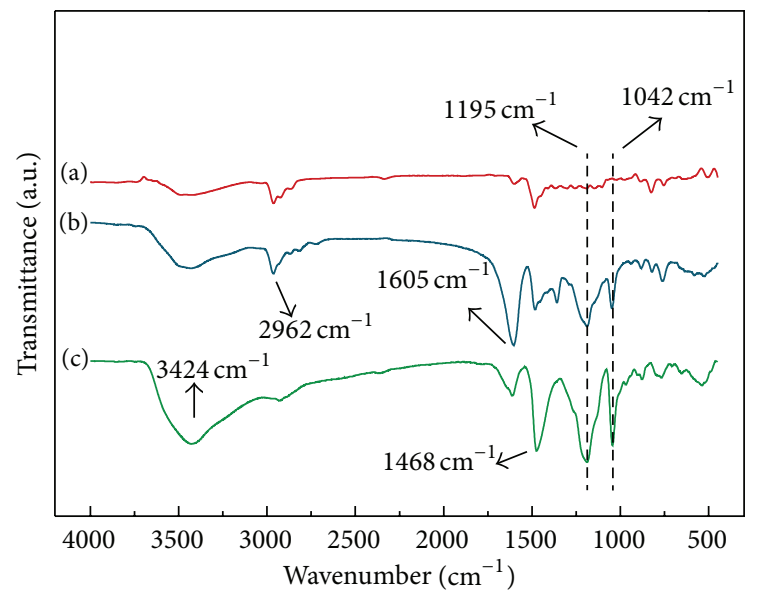

(a) Residues

(b) RPF

(c) $\mathrm{PF}$

FIGURE 4: FTIR spectra of the residues, RPF, and PF.

corresponded to the carbon-carbon double bond stretching vibration of the benzene ring skeleton. An observable sulfonate group antisymmetric stretching vibration band at $1195 \mathrm{~cm}^{-1}$ and a carbon-sulfur bond stretching band at $1042 \mathrm{~cm}^{-1}$ can be found in the spectrum of RPF and PF but not in the spectrum of the residues. This feature is considered to be characteristic of the sulfonation reaction.

Gas chromatography-mass spectrometry (GC-MS) is used to isolate and determine the organic molecules. The chromatogram of residues is depicted in Figure 5(a). Separation and peak profiles are accomplished in $30 \mathrm{~min}$ and several components can be isolated. The component contents (with the retention time of $6.8 \mathrm{~min}, 8.8 \mathrm{~min}, 14.0 \mathrm{~min}, 21.5 \mathrm{~min}$, and $22.9 \mathrm{~min}$ ) are $34.5 \%, 7.6 \%, 5.6 \%, 24.6 \%$, and $6.4 \%$, respectively (Table 2). Figures 5(b), 5(c), 5(d), 5(e), and 5(f) show the partial mass spectra of these five constituents
TABLE 1: Levels and factors affecting the fluid-loss properties.

\begin{tabular}{lcccccc}
\hline \multirow{2}{*}{ Levels } & \multicolumn{6}{c}{ Factors } \\
& $A\left({ }^{\circ} \mathrm{C}\right)^{\mathrm{a}}$ & $B^{\mathrm{b}}$ & $C^{\mathrm{c}}$ & $D^{\mathrm{d}}$ & $E(\mathrm{~mL})^{\mathrm{e}}$ & $F(\mathrm{~h})^{\mathrm{f}}$ \\
\hline 1 & 60 & 2.77 & 17.12 & 3.61 & 29.7 & 3 \\
2 & 70 & 1.39 & 5.71 & 2.71 & 39.6 & 4 \\
3 & 80 & 0.93 & 3.42 & 1.80 & 49.5 & 5 \\
4 & 90 & 0.69 & 2.45 & 1.20 & 59.4 & 6 \\
5 & 100 & 0.56 & 1.90 & 0.90 & 69.3 & 7 \\
\hline
\end{tabular}

${ }^{a} A$ : reaction temperature.

${ }^{\mathrm{b}} B$ : mass ratio of residue to formaldehyde.

${ }^{\mathrm{C}} \mathrm{C}$ : mass ratio of residue to catalyst.

${ }^{\mathrm{d}} D$ : mass ratio of residue to sulfonating agent.

${ }^{\mathrm{e}} E$ : amount of water.

${ }^{\mathrm{f}} F$ : reaction time.

TABLE 2: GC/MS results of the residues.

\begin{tabular}{lcccc}
\hline Peak & $\begin{array}{c}\text { Retention time } \\
(\mathrm{min})\end{array}$ & Assignments & $\begin{array}{c}\text { Molecular } \\
\text { ion }\end{array}$ & Content (\%) \\
\hline $1^{\#}$ & 6.8 & Phenol & 94.0 & 34.5 \\
$2^{\#}$ & 21.5 & $\mathrm{~A}^{\mathrm{a}}$ & 268.0 & 24.6 \\
$3^{\#}$ & 8.8 & Undecane & 156.0 & 7.6 \\
$4^{\#}$ & 14.0 & $\mathrm{~B}^{\mathrm{b}}$ & 174.0 & 5.6 \\
$5^{\#}$ & 22.9 & $\mathrm{C}^{\mathrm{c}}$ & 268.0 & 6.4 \\
\hline
\end{tabular}

a A: 3-(2-hydroxyphenyl)-1,1,3-trimethyl-2,3-dihydro-1H-inden-5-ol.

${ }^{\mathrm{b}} \mathrm{B}$ : 1,5,7-trimethyl-1,2,3,4-tetrahydronaphthalene.

${ }^{\mathrm{c}} \mathrm{C}$ : 3-(4-hydroxyphenyl)-1,1,3-trimethyl-2,3-dihydro-1H-inden-5-ol.

marked as $1^{\#}, 2^{\#}, 3^{\#}, 4^{\#}$, and $5^{\#}$. The molecular ions in the two main components, $1^{\#}$ and $2^{\#}$, have $m / z$ values of 94 and 268 , respectively, suggesting that number 1 is phenol, number 2 is 3-(2-hydroxyphenyl)-1,1,3-trimethyl-2,3-dihydro-1Hinden-5-ol. Phenol has already been used to produce phenolic resin and sulfonated phenolic resin. Number 2 has two phenolic hydroxyl groups, so it could condense with formaldehyde as well. 


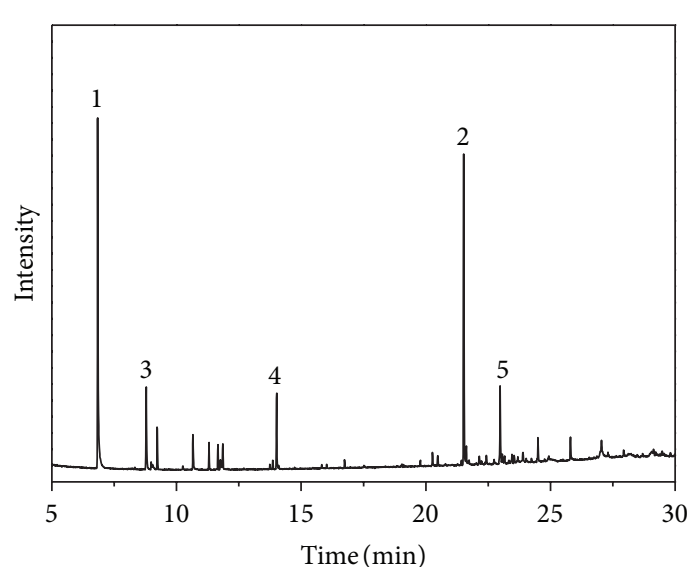

(a)

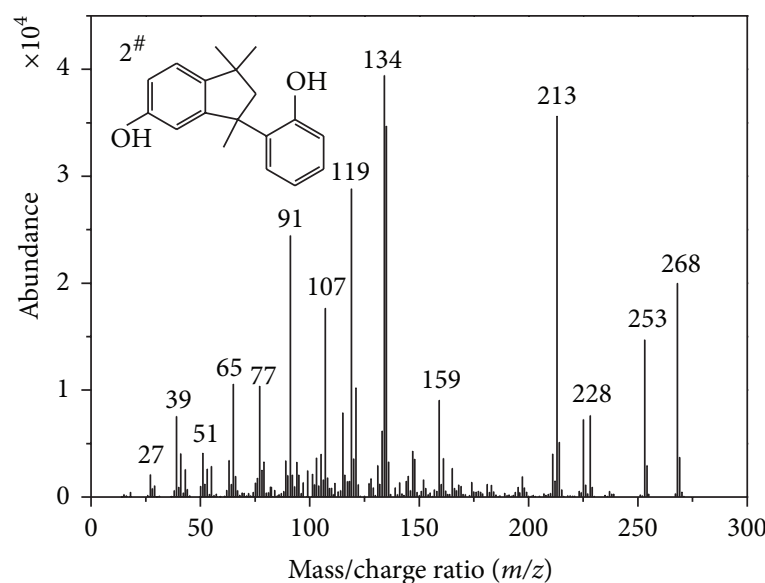

(c)

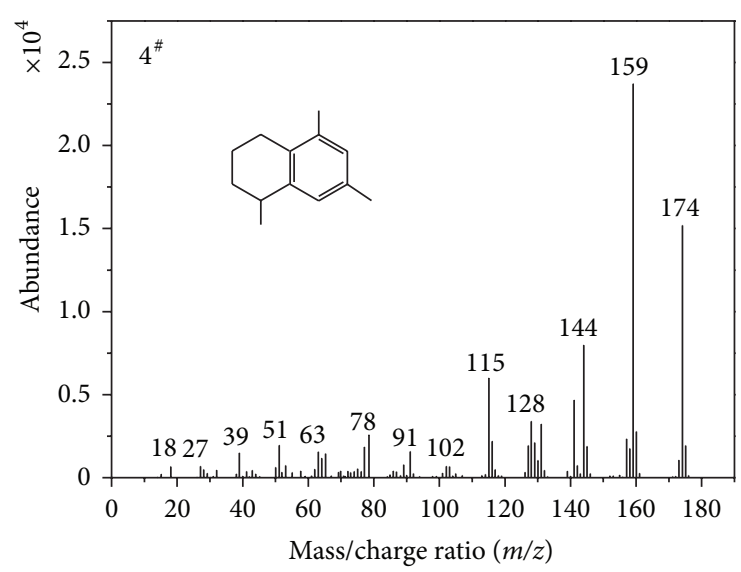

(e)

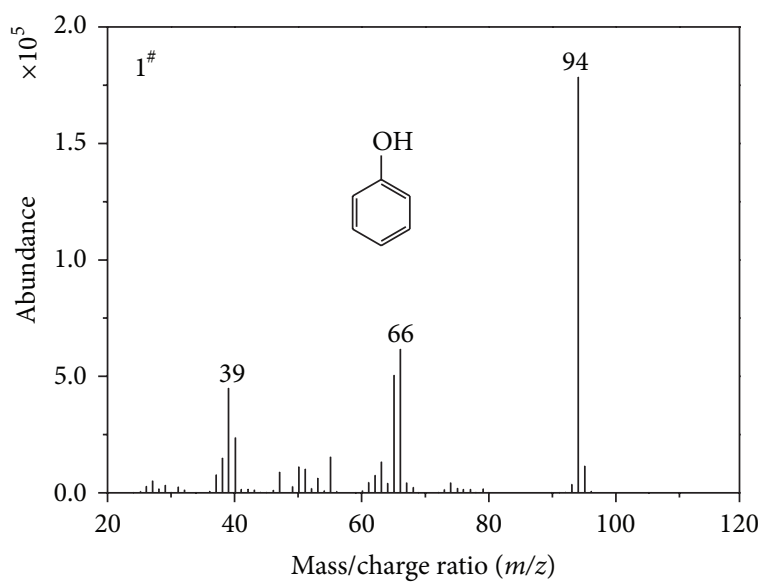

(b)

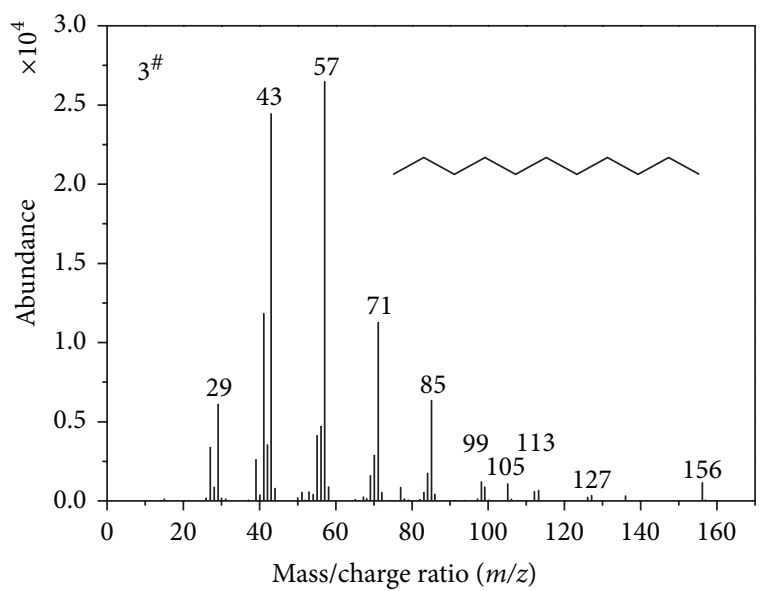

(d)

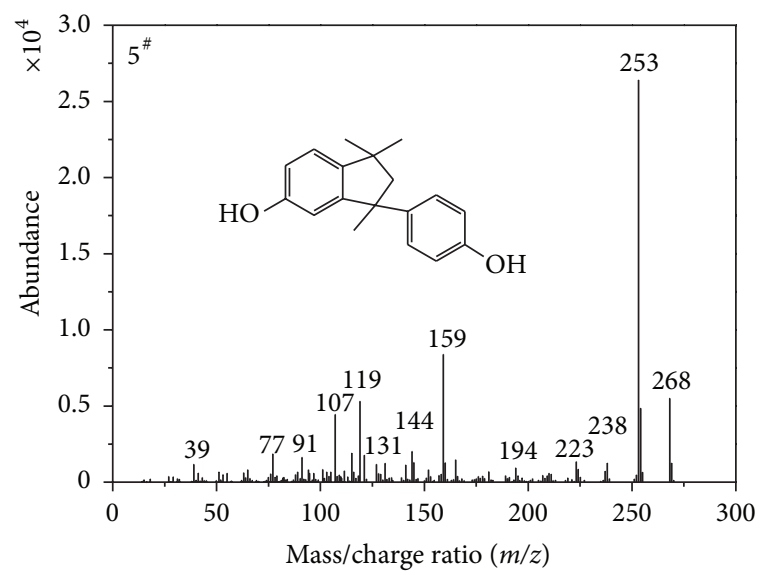

(f)

Figure 5: Chromatogram of the residues (a) and mass spectra of the five components from the residues (peaks 1-5 in the chromatogram) at different retention times of (b) $6.8 \mathrm{~min}$, (c) $21.5 \mathrm{~min}$, (d) $8.8 \mathrm{~min}$, (e) $14.0 \mathrm{~min}$, and (f) $22.9 \mathrm{~min}$.

There are many components in the residues. Some of the components have little content, similar structures, and polarity. Hence, it is difficult to separate the components absolutely. In our column chromatography experiments, there are five components obtained and the two main components are further identified by ${ }^{1} \mathrm{H} \mathrm{NMR}$ and the results are in agreement with those from GC-MS. As shown in Figure 6(a), the signal at $5.051 \mathrm{ppm}$ corresponds to the hydroxyl group (1). In the region of 6.8-7.3 ppm, there are signals assigned to the aromatic protons $(2,3$, and 4$)$. Hence, compounds number 1 is indeed phenol, also known as carbolic acid. In Figure 6(b), the resonance at $5.388 \mathrm{ppm}$ corresponds to 


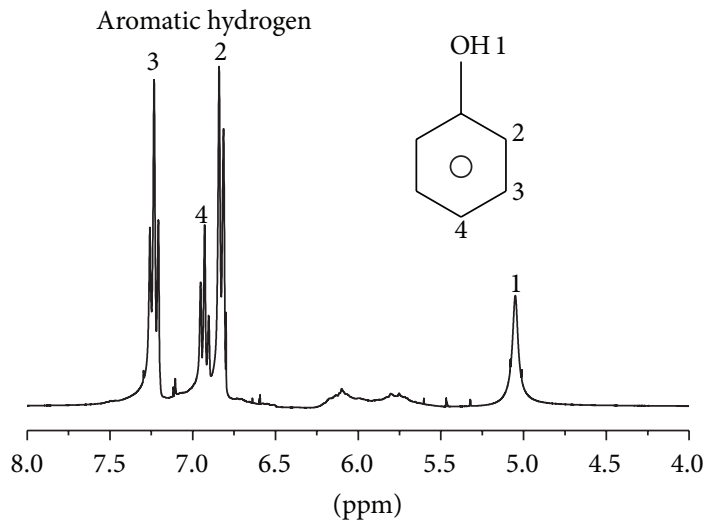

(a)

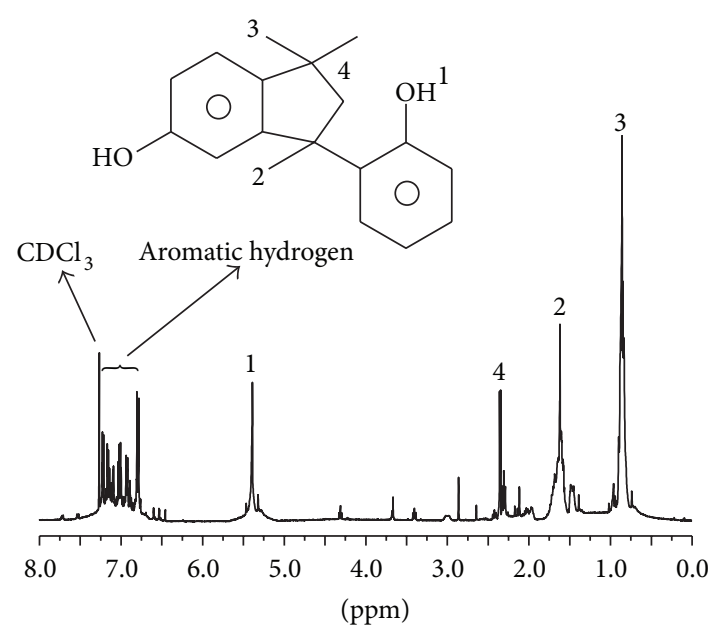

(b)

FIGURE 6: Proton nuclear magnetic resonance spectrum acquired from the two main components of the residues.<smiles>O=[Se+]([O-])c1cccc(Cc2cccc(Cc3cccc(Cc4ccccc4)c3O)c2O)c1</smiles>

(a)

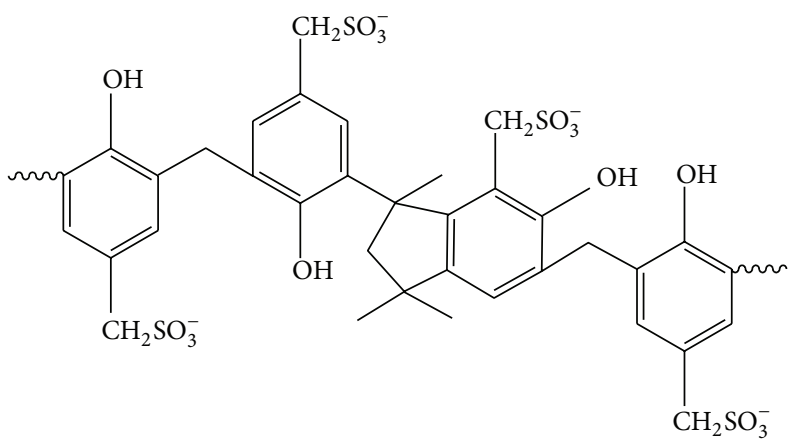

(b)

FIGURE 7: Structural representation of PF and RPF.

the hydroxyl group (1). The signals at $1.619 \mathrm{ppm}, 0.858 \mathrm{ppm}$, and $2.346 \mathrm{ppm}$ arise from protons 2,3 , and 4 , respectively. In the region of 6.683-7.267 ppm, there are signals assigned to the aromatic protons and deuterated chloroform. Thus, number 2 is identified to be 3-(2-hydroxyphenyl)-1,1,3-trimethyl2,3-dihydro- $1 \mathrm{H}$-inden-5-ol.

Hydroxyl is an ortho-para directing group. Due to the reactive positions, these two components could be condensed and sulfonated under the presence of formaldehyde and sodium sulfite. The simple schematic diagrams of the production were shown in Figure 7; (a) was PF and (b) was RPF. This is not the real structure but a possible structure that imaged to illustrating the condensation polymerization and the sulfonation reaction. The real structure of the reaction products will be more complex. The other components do not play a major role in this study because of the relatively tiny amount or the absence of active functional group.

\subsection{Effect of Formulas and Parameters on Filtration Properties.} There are two important parameters in range analysis: $K_{i j}$ and $R_{i} . K_{i j}$ is defined as the sum of the evaluation indexes of all levels $(j=1,2,3,4)$ in each factor $(i=A, B, C, D)$.
$K_{i j}^{\prime}$ (mean value of $K_{i j}$ ) is used to determine the optimal level and the optimal combination of factors. The optimal level for each factor could be obtained when $K_{i j}^{\prime}$ is the largest. $R_{i}$ is defined as the range between the maximum and minimum value of $K_{i j}^{\prime}$ and is used for evaluating the importance of the factors [23]. According to the OA25 matrix, twenty-five experiments were carried out and their filtrate volume results were shown in Table 3 . This table shows that the range of $\mathrm{FL}_{\mathrm{API}}$ was from $10 \mathrm{~mL}$ to $30 \mathrm{~mL}$ and the range of $\mathrm{FL}_{\mathrm{HTHP}}$ was from $50 \mathrm{~mL}$ to $138 \mathrm{~mL}$. The mean values of $K\left(K_{i j}^{\prime}\right)$ for different factors at different levels in the range analysis were shown in Table 4. As mentioned, for each factor, the higher mean value $\left(K_{i j}^{\prime}\right)$ indicates the larger effect on filtration loss. As shown in Table 4, for API filtrate properties, $K_{i j}^{\prime}$ was the lowest at these combinations $A_{4} B_{4} C_{2} D_{5} E_{3} F_{1}$, and, for HTHP properties, $K_{i j}^{\prime}$ was the lowest at $A_{1} B_{2} C_{5} D_{3} E_{4} F_{1}$. Compared with the range values of different factors $\left(R_{i}\right)$, the factors' levels of significance are as follows: for API, $C(6.10)>B$ (4.20), $F(4.20)>A(3.70)>D(3.48)>E$ (3.12); for HTHP, $A(31.20), B(31.20)>E(27.60)>C(26.00)>D(19.60)>F$ (16.00). 
TABLE 3: $\mathrm{FL}_{\mathrm{API}}$ and $\mathrm{FL}_{\mathrm{HTHP}}$ in OA25 matrix.

\begin{tabular}{|c|c|c|c|c|c|c|c|c|}
\hline \multirow{2}{*}{ Trial number } & \multicolumn{5}{|c|}{ Factors } & \multicolumn{3}{|c|}{ Results } \\
\hline & A & $B$ & C & $D$ & $E$ & $F$ & $\mathrm{FL}_{\mathrm{API}}(\mathrm{mL})$ & $\mathrm{FL}_{\mathrm{HTHP}}(\mathrm{mL})$ \\
\hline 1 & 1 & 1 & 1 & 1 & 1 & 1 & 22 & 78 \\
\hline 2 & 1 & 2 & 2 & 2 & 2 & 2 & 23 & 72 \\
\hline 3 & 1 & 3 & 3 & 3 & 3 & 3 & 24 & 60 \\
\hline 4 & 1 & 4 & 4 & 4 & 4 & 4 & 20 & 72 \\
\hline 5 & 1 & 5 & 5 & 5 & 5 & 5 & 20 & 90 \\
\hline 6 & 2 & 1 & 2 & 3 & 4 & 5 & 19 & 72 \\
\hline 7 & 2 & 2 & 3 & 4 & 5 & 1 & 27 & 92 \\
\hline 8 & 2 & 3 & 4 & 5 & 1 & 2 & 22 & 100 \\
\hline 9 & 2 & 4 & 5 & 1 & 2 & 3 & 25 & 126 \\
\hline 10 & 2 & 5 & 1 & 2 & 3 & 4 & 30 & 138 \\
\hline 11 & 3 & 1 & 3 & 5 & 2 & 4 & 26 & 110 \\
\hline 12 & 3 & 2 & 4 & 1 & 3 & 5 & 23 & 104 \\
\hline 13 & 3 & 3 & 5 & 2 & 4 & 1 & 18 & 50 \\
\hline 14 & 3 & 4 & 1 & 3 & 5 & 2 & 26 & 124 \\
\hline 15 & 3 & 5 & 2 & 4 & 1 & 3 & 26 & 116 \\
\hline 16 & 4 & 1 & 4 & 2 & 5 & 3 & 20 & 74 \\
\hline 17 & 4 & 2 & 5 & 3 & 1 & 4 & 22 & 56 \\
\hline 18 & 4 & 3 & 1 & 4 & 2 & 5 & 26 & 104 \\
\hline 19 & 4 & 4 & 2 & 5 & 3 & 1 & 10 & 86 \\
\hline 20 & 4 & 5 & 3 & 1 & 4 & 3 & 27 & 108 \\
\hline 21 & 5 & 1 & 5 & 4 & 3 & 2 & 21 & 60 \\
\hline 22 & 5 & 2 & 1 & 5 & 4 & 3 & 25 & 68 \\
\hline 23 & 5 & 3 & 2 & 1 & 5 & 4 & 20 & 90 \\
\hline 24 & 5 & 4 & 3 & 2 & 1 & 5 & 25 & 112 \\
\hline 25 & 5 & 5 & 4 & 3 & 2 & 1 & 24 & 96 \\
\hline
\end{tabular}

TABLE 4: Range analysis data of the $\mathrm{FL}_{\mathrm{API}}$ and $\mathrm{FL}_{\mathrm{HTHP}}$.

\begin{tabular}{lcccccc}
\hline Value name & $A$ & $B$ & $C$ & $D$ & $E$ & $F$ \\
\hline \multicolumn{7}{c}{$\mathrm{FL}_{\text {API }}$} \\
$K_{1}^{\prime}$ & 21.80 & 21.78 & 25.80 & 23.40 & 23.40 & 20.30 \\
$K_{2}^{\prime}$ & 24.70 & 24.00 & 19.70 & 23.30 & 24.80 & 23.10 \\
$K_{3}^{\prime}$ & 23.90 & 22.10 & 25.80 & 23.10 & 21.68 & 24.50 \\
$K_{4}^{\prime}$ & 21.00 & 21.20 & 21.80 & 24.08 & 22.00 & 23.60 \\
$K_{5}^{\prime}$ & 23.08 & 25.40 & 21.38 & 20.60 & 22.60 & 22.70 \\
$R$ & 3.70 & 4.20 & 6.10 & 3.48 & 3.12 & 4.20 \\
\hline \multicolumn{7}{c}{$\mathrm{FL}_{\mathrm{HTHP}}$} \\
$K_{1}^{\prime}$ & 74.40 & 78.80 & 102.40 & 101.20 & 92.40 & 80.40 \\
$K_{2}^{\prime}$ & 105.60 & 78.40 & 87.20 & 89.20 & 101.60 & 89.00 \\
$K_{3}^{\prime}$ & 100.80 & 80.80 & 96.40 & 81.60 & 89.60 & 92.00 \\
$K_{4}^{\prime}$ & 85.60 & 104.00 & 89.20 & 88.80 & 74.00 & 93.20 \\
$K_{5}^{\prime}$ & 85.20 & 109.60 & 76.40 & 90.80 & 94.00 & 96.40 \\
$R$ & 31.20 & 31.20 & 26.00 & 19.60 & 27.60 & 16.00 \\
\hline
\end{tabular}

3.3. Filtration Properties. According to the optimal conditions shown above, we have changed and modified the experiment conditions and parameters and finally prepared the fluid-loss-control additive RPF and PF. As a fluid-losscontrol additive, RPF and PF could improve the properties of drilling fluid. Series of fresh-water and salt-water mud

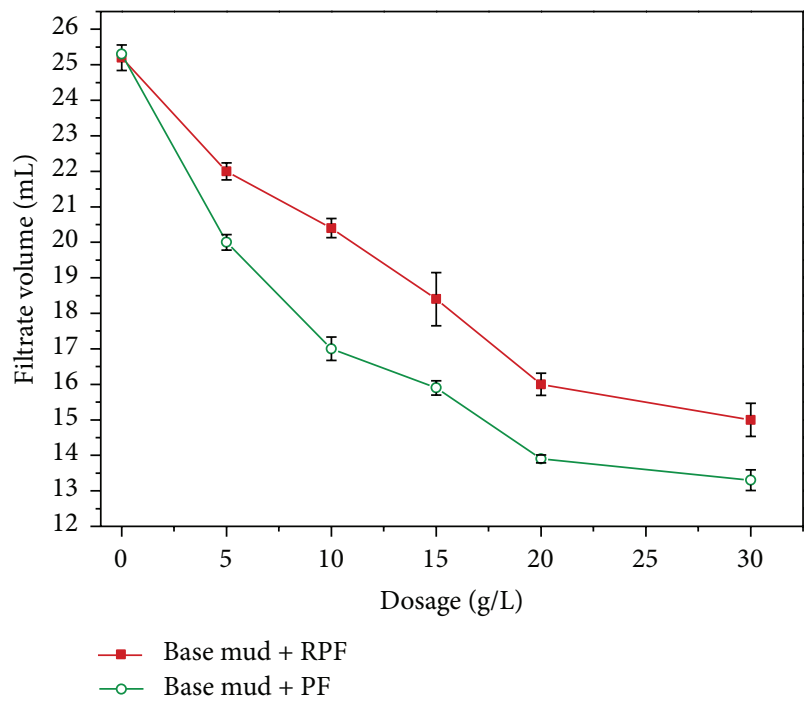

FIGURE 8: The effect of RPF and PF concentration on the API filtration loss of fresh water mud.

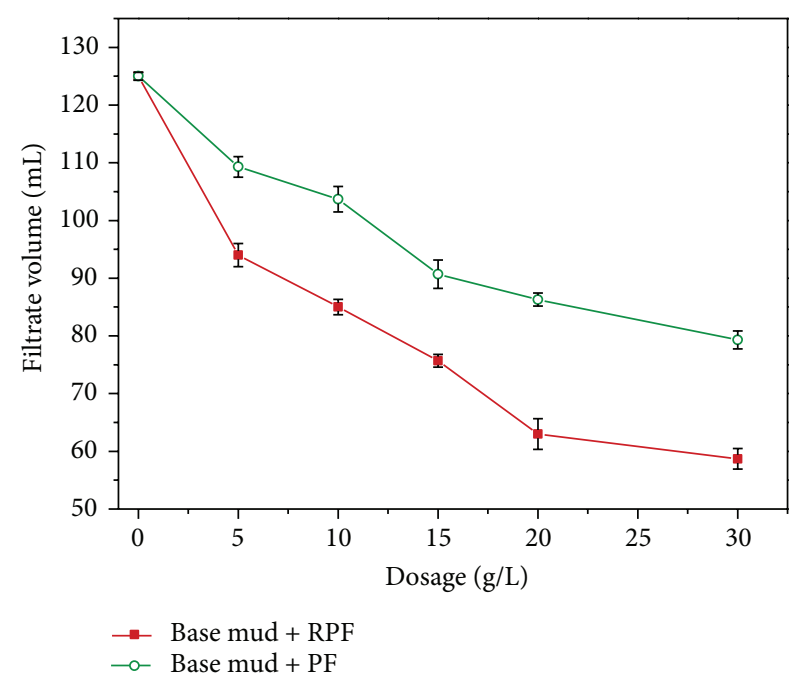

FIGURE 9: The effect of RPF and PF concentration on the HTHP filtration loss of fresh water mud.

formulations were prepared, and the filtrate volumes were measured. To probe into the effect of dosage of the fluid-losscontrol additive on filtration properties, test of API filtration, and HTHP filtration were performed. From Figures 8 and 9 , it can be observed that the fluid-loss volumes decreased with more additives used. These additives dispersed into the base mud and then could be adsorbed onto the clay surface under the action of hydrogen bond between the hydroxyl and the clay surface [24]. So, there exists a saturated adsorption amount. When the additive addition was over dose, the excess additives have little influence on filtration properties. As shown in Figures 8 and 9, when the concentration of the additive was higher than $20 \mathrm{~g} / \mathrm{L}$, the fluid-loss volumes decreased slowly. 
From the analysis shown in Figures 5 and 6 and the possible structure of the product shown in Figure 7, it was expected that RPF would have better HTHP filtrate properties than PF. Segmental motion of molecular chain is dependence on temperature. The higher the temperature is, the more intense the segmental motion is. When the segmental motion is intense enough, molecular repulsion will be stronger than attraction and the molecular chain breaks. This was called degradation. There are two situations when polymer degrades; the molecular weight of the additive decreases and the amount of functional group of the additive decreases. These situations would cause the fluidloss-control performance deterioration. Polymer will degrade at high temperatures, but the degree of the degradation is different because of the different molecular structure. If there are more aromatic groups in the molecular chain, the chain segments are bigger, and the temperature needs to be higher to make the segments motion. 3-(2-Hydroxyphenyl)1,1,3-trimethyl-2,3-dihydro- $1 \mathrm{H}$-inden-5-ol and phenol are the main components in the residues. Phenol condensation polymer is endowed well HTHP fluid-loss-control performance by introducing benzene ring into the molecular structure. 3-(2-Hydroxyphenyl)-1,1,3-trimethyl-2,3-dihydro$1 \mathrm{H}$-inden-5-ol has the activation group hydroxyl, and the molecular structure is more rigid than phenol. So, the resultant additives will have well HTHP fluid-loss-control performance by using these residues.

There are two competitive factors that affect the fluidloss-control performance of RPF. (1) The components in the residue are complex, and some of them do not have the essential reactive group. These components cannot participate in the reaction and have no effect to improve the HTHP performance. (2) Most of the components in the residue are aromatic derivative, and they have the same reactive group like phenol. These components have the essential functional group as fluid-loss-control additives. Meanwhile, the side chain of the RPF molecular is bigger by introducing these aromatic derivatives into the condensation reaction as the constitutional unit than introducing phenol. The bigger side chain provides RPF better thermostability.

It can be seen in Figure 9 that the HTHP fluid-losscontrol performance of RPF is better than PF. This can be explained as, in the fresh water mud, the thermo stability of the molecular chain is more important for the HTHP performance than the amount of the functional groups. The positive effect of the rigid molecular structure of the aromatic derivatives is more than the negative effect of the inactive components. This is why fewer components in residue could result in better HTHP fluid-loss-control performance in fresh water mud of RPF than that of PF.

To show the stability of RPF as a fluid-loss-control additive in saline solutions, filtration loss test of $20 \mathrm{~g} / \mathrm{L}$ additive in $50 \mathrm{~g} / \mathrm{L}$ bentonite mud with $40 \mathrm{~g} / \mathrm{L} \mathrm{NaCl}$ was performed. It is important to have additive for drilling mud that are stable in saline environments. Without additive, bentonite mud would lose its fluid-loss-control properties. According to the DLVO theory, it is thought to be explained as that the electrolyte solutions will compress the electrostatic double layer, affect hydration and coagulation stability of clays, and lead to

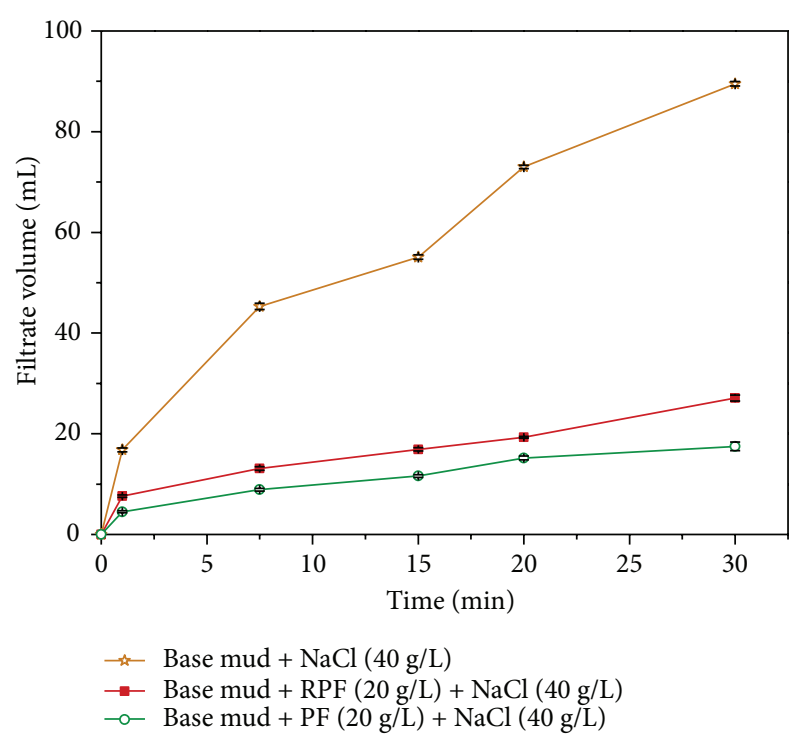

Figure 10: API filtration loss of RPF and PF in base mud and $\mathrm{NaCl}$ $(40 \mathrm{~g} / \mathrm{L})$ solutions.

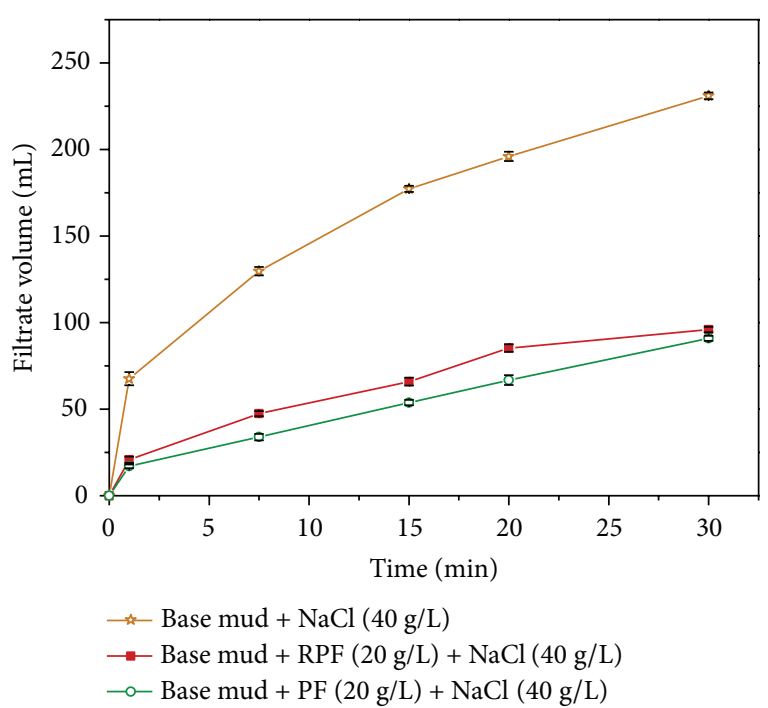

FIGURE 11: HTHP filtration loss of RPF and PF in base mud and $\mathrm{NaCl}$ $(40 \mathrm{~g} / \mathrm{L})$ solutions.

the dehydration of the additives. Therefore, salt resistance additives should have enough adsorbing groups to connect with the clay surface and enough hydration groups to control the free water, and the hydration groups should be insensitive to electrolyte. The RPF have phenolic hydroxyl groups as the adsorbing groups and sulfonate groups as the hydration groups which have been proved to have well salt resistance [25]. RPF was expected to have salt resistance like PF. From the experiments data shown in Figures 10 and 11, unlike the expected results, RPF took a relatively poor effect compared with PF. It might be caused by the less active ingredient content. In the presence of salt solutions, the content of sulfonate groups plays the major role of the salt resistance. There are some inactive components in the residues, which 
TABLE 5: Properties of RPF compared to commercial fluid-losscontrol additives.

\begin{tabular}{lccccc}
\hline $\begin{array}{l}\text { Fluid-loss-control } \\
\text { additive }^{\mathrm{a}}\end{array}$ & $\begin{array}{c}\mathrm{AV} \\
(\mathrm{mPa} \cdot \mathrm{s})\end{array}$ & $\begin{array}{c}\mathrm{PV} \\
(\mathrm{mPa} \cdot \mathrm{s})\end{array}$ & $\begin{array}{c}\mathrm{YP} \\
(\mathrm{Pa})\end{array}$ & $\begin{array}{c}\mathrm{FL}_{\mathrm{API}} \\
(\mathrm{mL})\end{array}$ & $\begin{array}{c}\mathrm{FL}_{\mathrm{HTHP}} \\
(\mathrm{mL})\end{array}$ \\
\hline $\mathrm{RPF}$ & 21.5 & 12.0 & 9.5 & 16.0 & 62.0 \\
$\mathrm{M}_{1}$ & 20.5 & 7.0 & 13.5 & 16.0 & 88.0 \\
$\mathrm{M}_{2}$ & 17.5 & 7.0 & 10.5 & 10.0 & 64.0 \\
$\mathrm{M}_{3}$ & 13.5 & 9.0 & 4.5 & 11.0 & 66.0 \\
$\mathrm{M}_{4}$ & 14.0 & 8.0 & 6.0 & 12.0 & 72.0 \\
\hline
\end{tabular}

${ }^{\mathrm{a}}$ The dosage of fluid-loss-control additive was $20 \mathrm{~g} / \mathrm{L}$.

could not participate in the sulfonation reaction. However, from the experiment results shown in Figure 9, it is obvious that although the effective component is less, the HTHP performance is still better.

For comparison, the properties of RPF and some commercial fluid-loss-control additives were shown in Table 5. It can be seen that the API filtrate volume of RPF is $16 \mathrm{~mL}$ and the HTHP filtrate volume of RPF is $62 \mathrm{~mL}$. Through the comparison, it reveals that the HTHP performance of RPF is better than these commercial products. The viscosity of RPF is higher, and the yield point is in the middle.

\section{Conclusion}

The residue wastes produced from the BPA industry were complex compounds. Phenol and 3-(2-hydroxyphenyl)-1,1,3trimethyl-2,3-dihydro-1H-inden-5-ol were the two main components of the residues. The fluid-loss-control additive produced using the residues showed better HTHP fluid-losscontrol performance than some commercial products. This study indicates that the residues have potential application in fluid-loss-control additive manufacture. Using it to substitute phenol will improve the high temperature performance and endow the additive with significant cost advantage.

\section{Conflict of Interests}

All the authors declare that they have no conflict of interests.

\section{Disclaimes}

The paper is authors owned work, is original and unpublished, and is not being considered for publication elsewhere.

\section{Acknowledgments}

This work is jointly supported by the Special fund of coconstruction of Beijing Education Committee and the Fundamental Research Funds for the Central Universities no. 2652013062 .

\section{References}

[1] W. T. Tsai, "Human health risk on environmental exposure to Bisphenol-A: a review," Journal of Environmental Science and Health, vol. 24, no. 2, pp. 225-255, 2006.
[2] P. Michele and C. Giuseppe, Braz. Pedido PI BR, 7, 903, 483, 1979.

[3] V. N. Sheemol, I. R. Unni, and C. Gopinathan, "Catalysis by heteropoly acids: formation of bisphenol A from phenol and acetone," Indian Journal of Chemical Technology, vol. 8, no. 4, pp. 298-300, 2001.

[4] A. E. Donald, B. R. Lawrence, C. Ye-mon, and J. R. Lawrence, Upflow Fixed Bed Reactor With Packing Elements, WO Patent, 1997.

[5] C. D. Nenitescu, Chimie Organica, vol. 2, p. 47, 1980.

[6] Z. N. Verkhovskaya, M. Ya. Klimenko, L. B. Vystavkina et al., "Composition of the by-products of diphenylolpropane synthesis and their recovery," Neftpererab Nefekhim, vol. 5, pp. 34-35, 1973.

[7] A. V. Krishnan, P. Stathis, S. F. Permuth, L. Tokes, and D. Feldman, "Bisphenol-A: an estrogenic substance is released from polycarbonate flasks during autoclaving," Endocrinology, vol. 132, no. 6, pp. 2279-2286, 1993.

[8] C. A. Staples, P. B. Dorn, G. M. Klecka, S. T. O’Block, and L. R. Harris, "A review of the environmental fate, effects, and exposures of bisphenol A," Chemosphere, vol. 36, no. 10, pp. 21492173, 1998.

[9] F. Jiao, X. Sun, and Z. Pang, "Production and market analysis of Bisphenol A," Chemistry \& Industry, vol. 26, pp. 21-33, 2008.

[10] S. Evitt, C. Chi, M. S. Lee, and D. Palmer, Process For Recovering Phenol From A BPA Waste Stream, 2010.

[11] J. C. Carnahan, Phenol Recovery From Bisphenol-A Waste Streams, 1981.

[12] S. J. Shafer, J. Pressman, and J. L. Lee, Method For Recovering Material Values From Bisphenol Tars, 2001.

[13] K. K. Chang, M. C. Clingerman, M. L. Lott, and J. T. Schneider, Use of Bisphenol A tar in furan No-bake Foundry Binders, 1999.

[14] P. L. Moore, Drilling Practices Manual, The Petroleum Publishing, Tulsa, Oklahoma, 1974.

[15] C. L. William and J. P. Gary, Standard Handbook of Petroleum \& Natural Gas Engineeringed, Gulf Professional Publishing, Houston, Tex, USA, 2nd edition, 1996.

[16] A. D. Patel, E. Stamatkis, and E. Davids, U.S. Patent 6, 247, 543, 2001.

[17] J. McDermott, Drilling Mud and Fluid Additives, Noyes Data Corp, London, UK, 1973.

[18] K. C. Hsu and Y. F. Lee, "Water-soluble sulfonated phenolic resins. I. Synthesis," Journal of Applied Polymer Science, vol. 57, pp. 1419-1537, 1995.

[19] J. J. M. Nahm and D. A. Rowe, U.S. Patent 3, 956, 140, 1976.

[20] S. Rukzon and P. Chindaprasirt, "Utilization of bagasse ash in high-strength concrete," Materials and Design, vol. 34, pp. 4550, 2012.

[21] W. Wang and G. Huang, "Characterisation and utilization of natural coconut fibres composites," Materials and Design, vol. 30, no. 7, pp. 2741-2744, 2009.

[22] H. Y. Aruntas, M. Gürüb, M. Dayı, and T. İlker, "Utilization of waste marble dust as an additive in cement production," Materials \& Design, vol. 31, no. 8, pp. 4039-4042, 2010.

[23] C. Chuanwen, S. Feng, L. Yuguo, and W. Shuyun, "Orthogonal analysis for perovskite structure microwave dielectric ceramic 
thin films fabricated by the RF magnetron-sputtering method," Journal of Materials Science, vol. 21, no. 4, pp. 349-354, 2010.

[24] D. J. Greenland, "Adsorption of polyvinyl alcohols by montmorillonite," Journal of Colloid Science, vol. 18, no. 7, pp. 647-664, 1963.

[25] U. P. Strauss and Y. P. Leung, "Volume changes as a criterion for site binding of counterions by polyelectrolytes," Journal of the American Chemical Society, vol. 87, no. 7, pp. 1476-1480, 1965. 

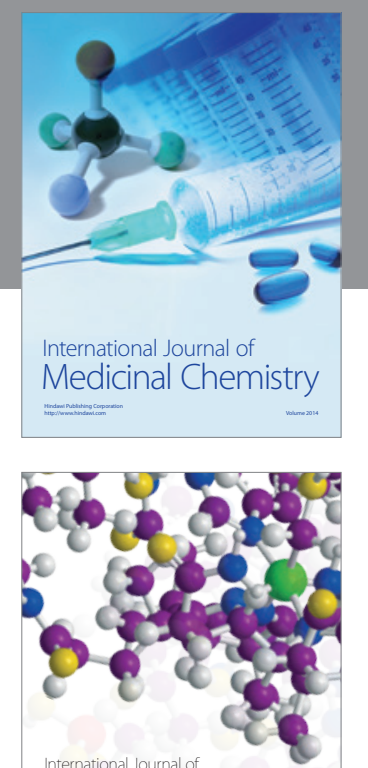

\section{Carbohydrate} Chemistry

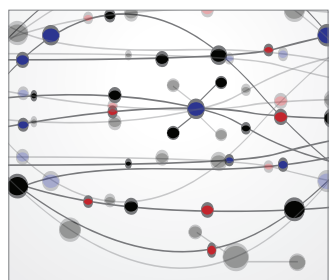

The Scientific World Journal
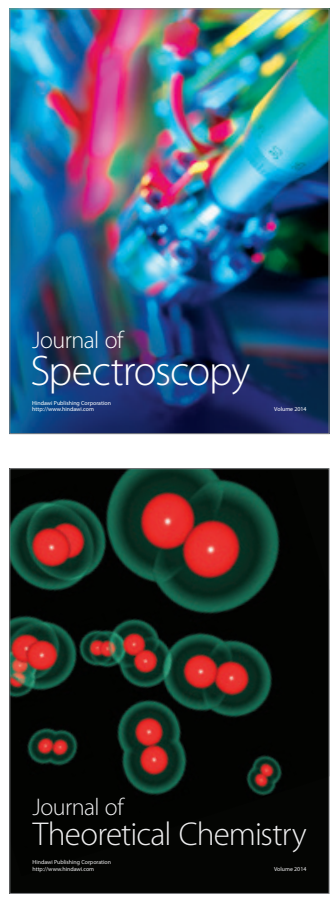
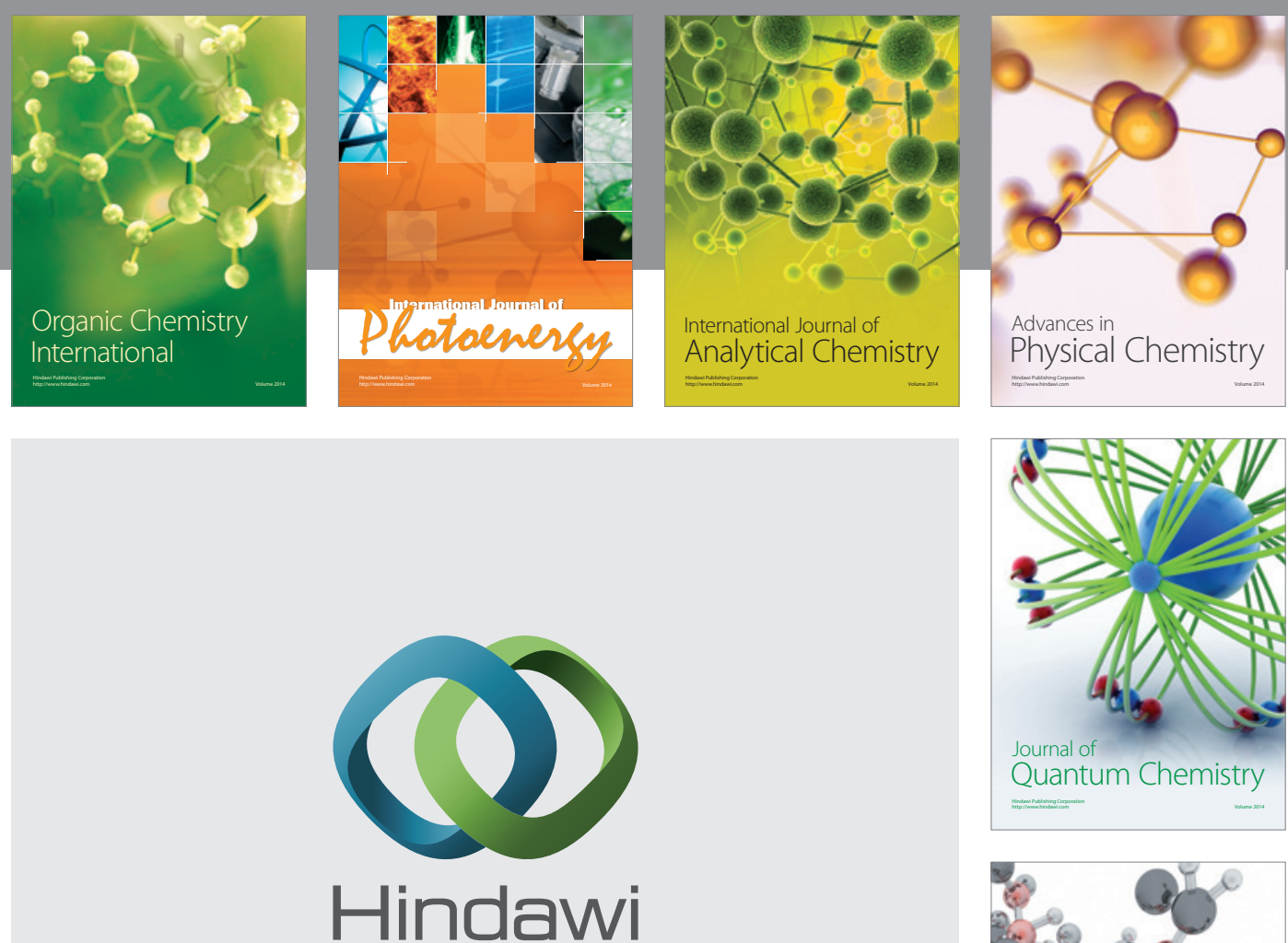

Submit your manuscripts at

http://www.hindawi.com

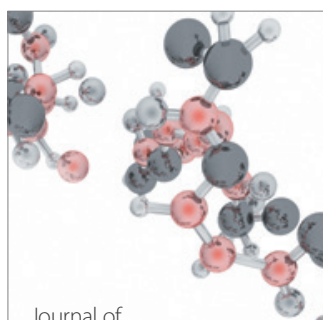

Analytical Methods

in Chemistry

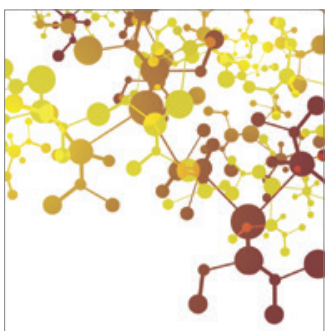

Journal of

Applied Chemistry

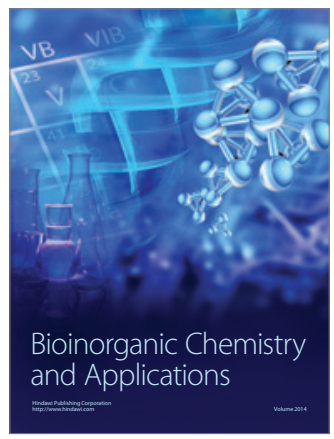

Inorganic Chemistry
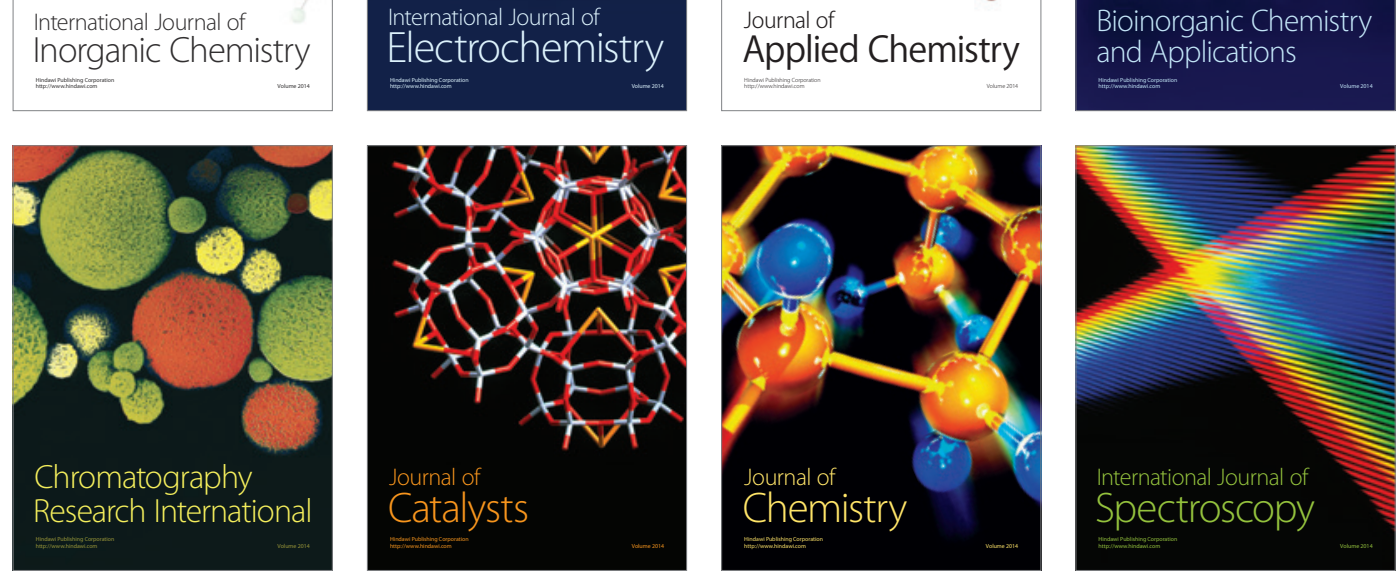